\title{
The Trumpeter
}

Journal of Ecosophy

\section{Ecological Self from an Aesthetic Point of View}

\section{Gérald Hess}

Volume 33, Number 1, 2017

URI: https://id.erudit.org/iderudit/1050861ar

DOI: https://doi.org/10.7202/1050861ar

See table of contents

Publisher(s)

Athabasca University Press

ISSN

1705-9429 (digital)

Explore this journal

Cite this article

Hess, G. (2017). Ecological Self from an Aesthetic Point of View. The Trumpeter, 33(1), 1-22. https://doi.org/10.7202/1050861ar

\section{Article abstract}

The present article develops an aesthetic signification for the idea of an ecological self proposed by Arne Næss and for its underlying relationship of identification. It is based on a discussion of a model of environmental aesthetics - the mystery model - by Stan Godlovitch. Godlovitch has presented his model as an alternative to the cognitive paradigm developed by Allen Carlson. While showing the value of this acentric aesthetic, I am proposing a different version of this model founded on a phenomenological approach - by French philosopher Maurice Merleau-Ponty. This perspective provides a better understanding of a subject's attitude of insignificance and aesthetic aloofness inherent in an acentric aesthetic experience of nature. It also shows what brings together and separates this experience, first from death, and secondly from mysticism. In so doing, it helps establish the legitimacy of the concept of the ecological self by looking at it in a new way.
This document is protected by copyright law. Use of the services of Erudit (including reproduction) is subject to its terms and conditions, which can be viewed online.

https://apropos.erudit.org/en/users/policy-on-use/ 


\section{Ecological Self from an Aesthetic Point of View}

Gérald Hess

\section{Introduction}

I find I incorporate gneiss, coal, long-threaded moss, fruits, grains, esculent roots, And am stucco'd with quadrupeds and birds all over, And have distanced what is behind me for good reasons,

But call any thing back again when I desire it.

This brief excerpt from Leaves of Grass $(1965,59)$ by Walt Whitman $(1819-1892)$ expresses in poetic language a unique relationship to nature. It attests to a radical decentering of the self, giving voice to an experience of nature itself, ${ }^{1}$ both mineral and vegetal, beyond any specific point of view. In short, nature is appreciated for its elementary presence, as an unfathomable and mysterious whole. ${ }^{2}$

This decentering of the self reflects a point of view that could be called the "View from Nowhere" as Thomas Nagel so aptly called it (1986). It is not an absence of perspective, but rather one from a subjective, particular viewpoint. Nagel has in mind the objective, conceptual "third-person" viewpoint through which material phenomena are apprehended by the natural sciences, as opposed to the subjective qualities of lived experience, perceptible only in reference to a "first-person" perspective. According to the author, these qualities elude scientific knowledge. In this context, the singularity of the quote from Whitman's book consists in expressing an experience (probably ephemeral) of the view from nowhere. Thus, this expression does not signify here the conceptual objectivity of science. Indeed, this experience demonstrates a perspective-of nature-that appears "objective" to the subject, yet is not conceptual: the poet's experience would thus involve a point of view that is never specific, or to use another of Nagel's well-known expressions, "There is something it is like to be..." neither this nor that, to be nothing coming from a privileged perspective (1974, emphasis added).

The experience of nature illustrated in the verse from Leaves of Grass (or my interpretation of it) is paradoxical to say the least, since it involves a "first-person" experience from a "third-person" point of view. It is not nearly an experience of myself in the "third person," but also an experience of others in the "first person." ${ }^{3}$ It seems to me to reflect, on anaesthetic level, one of the rare descriptions expressed by Arne Naess regarding self-

\footnotetext{
${ }^{1}$ The preposition "of" in the expression "experience of nature" must be understood here with the double meaning of "possessive" and "genitive." In the genitive sense, it involves an experience of nature experienced by the poet; in the possessive sense, the expression suggests the experience is undergone by nature.

${ }^{2}$ See the note from the editors about poem number 30 as a whole (Whitman 1965, 58-59).

${ }^{3}$ In technical terms, one could say this experience combines an allocentric type of "first person" perspective with an egocentric type of "third person" perspective (Gallagher 2002, 244).
} 
realization, a description that incidentally is based on Gestalt psychology: "Gestalts bind the I and the not-I together in a whole. Joy becomes, not my joy, but something joyful of which the I and something else are interdependent, non-isolatable fragments" (Naess 1989, 6061). And he continues with this poetic evocation: "The birch laughed/with the light easy laughter of all birches...' This gestalt, he says, is a creation which may only incompletely be divided to give an I which projects laughter into a non-laughing birch tree" (Naess 1989, 6061).

This idea of a "deep, comprehensive and ecological self" (Naess 1989, 175) was later clarified by philosophers of deep ecology such as Freya Mathews (1991) and Warwick Fox (1995) in particular. It has found fertile ground for expansion in phenomenology (Brown and Toadvine 2003; Vakoch and Castrillón 2014; Bannon 2016) and in psychology (Roszak, Gomes, and Kanner 1995; Rust and Totton 2012). But to my knowledge it has never been approached from an aesthetic perspective. This essay thus aims to clarify the signification of the ecological self and its underlying identification from the point of view of environmental aesthetics, in order to establish its legitimacy.

From this point of view, an experience of nature as described and illustrated in the above verse by Whitman raises the question of knowing if there exists an aesthetic theory capable of accounting for it. From the end of the 1970s, the philosopher Allen Carlson (1977, 1979 and 2004) showed the legitimacy of an aesthetics of nature, as distinct from fine arts aesthetics, and developed to that end a highly convincing cognitive model of aesthetic appreciation.

That model is extremely relevant in understanding the specificity of an aesthetic appreciation of the natural environment as compared to the aesthetics of fine arts. Carlson himself $(2008,2010)$ underlined the advantages of his model, which has provided among other things a theoretical basis for the positive aesthetics so dear to proponents of pristine nature and wilderness; it has also ensured the objectivity of aesthetic judgment that is vital for public policies to preserve the landscape. However, this model has struggled to give an account of an experience of nature like the one expressed in Whitman's verse, where the relationship between subject and object of aesthetic experience has virtually disappeared. Indeed, in Carlson's model the environment remains the objective correlative of an intentional relationship.

Beginning in the 1990s, Carlson's reflection prompted several alternative propositions that have greatly contributed to developing the field of environmental aesthetics. Among these propositions, an aesthetic sometimes known as the "mystery model" (Carlson 2014, 18) was elaborated by Stan Godlovitch (2004). This model endorses the idea that in order to appreciate nature "on its own terms" (Saito 2004, 141), it must be grasped through the point of view from nowhere. But at the same time, Godlovitch's model leads to an understanding of nature similar to one championed at one stage by a friend of Naess, the philosopher Peter Reed (1989), as an alternative to ecological self-realization, namely of nature's absolute otherness. Nevertheless, I think we can use Godlovitch's model to explore answers in the field of environmental aesthetics that are analogous to those put forward by Naess (1999) in the field of ecophilosophy. As I see it, adopting the point of view from nowhere toward nature-not in the sense of the sciences' objectivity to be sure, but rather in the sense of a return to the lived body-corresponds on an aesthetic level to ecological self-realization. This essay even suggests that such a realization is in fine aesthetic in nature. 
In order to understand how the response to Godlovitch's model is an alternative capable of illustrating an aesthetic signification of the ecological self and the identification process upon which it is based, later in this discussion (1) I will briefly introduce Godlovitch's model to show both its valuable contribution and its limits. Then, (2) I will develop another model of the aesthetics of mystery that is more relevant to the nature of aesthetic experiences, namely sensibility and the body. To do this, I will draw on contributions from phenomenology, in particular the French philosopher Maurice Merleau-Ponty, who is rarely, if ever, referred to in philosophical discussions on environmental aesthetics. Finally, (3) with the alternative model of an aesthetics of mystery, I will focus on exploring two underlying themes in Godlovitch's reflections that are never addressed directly: the mystical and death. The first of these two themes is often linked to the concept of the ecological self. Unless I am mistaken, the latter has never been linked in this way, but an acentric aesthetics of nature makes it possible to suggest a kind of affinity between the experience of death and the ecological self.

Within the framework ofenvironmental aesthetics, this study strives to shed new light on Naess' ecological self and the identification through which it can be realized. A wellunderstood aesthetics of the mystery of nature is in my view capable of making a crucial contribution to the significance of an ecological self. But more broadly, the present investigation also allows us to renew the meaning of a vision of nature conveyed by a long tradition in Western philosophy in which nature is seen as mysterious (Hadot 2006).

\section{Godlovitch's Mystery Model}

"Should an aesthetic appreciation of nature require us to respect scales of space and time which may have little significance from a human-centered perspective? If so, isn't it curious that the aesthetic dimension, rooted firmly and, some may argue, necessarily in the realities of human perception, should have to disavow that very limit when directed to the natural sphere?" (Godlovitch 2004, 109)

Godlovitch asks these questions about things in nature, the aesthetic value of which might bear no relation to the scale of a human life, either temporally or spatially. They reflect the mysterious side that emerges from an aesthetic experience of nature. This mystery is a constant in the long Western history of humanity's relationship to nature. ${ }^{4}$

From the standpoint of very long geological time, for instance, the current Arctic thawing from climate change might seem insignificant on an aesthetic level. Conversely, if we were to live for only a few days or months, every block of ice that broke off the ice shelf could quite well be catastrophic. On a spatial level, naturally we can compensate for our perceptive limits. With the help of technical instruments such as microscopes and satellites we are capable of seeing what is either too small or too far away for human perception. But we are thereby introducing an intermediary between the observer and the object observed.

\footnotetext{
${ }^{4}$ Hadot (2006) shows in a convincing manner the dual attitude that can be adopted regarding nature, as evidenced by the entire history of Western philosophy. On the one hand, the Promethean attitude strives to appropriate nature's secrets through scientific and technical knowledge; on the other hand, the Orphic attitude seeks to be initiated into the mysteries of nature through art and speculative philosophy, rather than to overcome its resistance by forcing out its secrets.
} 
That intermediary breaks off the physical immediacy or "somatic engagement" dear to Berleant (2004, 80-81), a feature of the aesthetic appreciation of the environment.

Godlovitch holds that an aesthetics of nature founded on human sensibility is necessarily arbitrary. Biological limitations constitute a bias that determines the kind of objects liable to be appreciated. Humans in fact suffer from the "sensory parochial" (Godlovitch 2004, 112). One could object that this kind of anthropocentrism is inevitable, its limits pertaining to our human condition. Natural aesthetics is therefore a centric type of aesthetics. Yet, to appreciate "nature as a whole" (Godlovitch 2004, 110), the author thinks that only an acentric vision of the environment will do. On an ethical level, it is entirely possible to find a way out of (moral) anthropocentrism, as a number of ethicists have suggested after Aldo Leopold (1949), without achieving true acentrism. ${ }^{5}$ Would it be possible to achieve it through environmental aesthetics? The difficulty of such an endeavor lies in the fact that all aesthetics-and, consequently, the aesthetics of nature-are by definition dependent on the senses and, more broadly, on sensibility. A truly acentric aesthetics must therefore go beyond "a sensory experience in the ordinary sense" and imagine a "non-sensory experiential framework" (Godlovitch 2004, 112).

Carlson's cognitive approach imagines the aesthetic experience of nature in that way. However, we have seen this as incompatible with the experience of an unfathomable and mysterious nature expressed by Whitman. And yet, admiration and respect, love and other feelings - of mysticism or of the sublime-are no more adequate, according to Godlovitch, in capturing the mystery of nature. Indeed, all these experiences of the environment remain expressions of a particular point of view. For Godlovitch, only one attitude can lead us to see the unknowable or the mysterious in nature: "aesthetic aloofness" and "insignificance" (2004, 121).

We appreciate nature aesthetically as a whole and as mysterious when we perceive it through a perspective that is "from nowhere" (Nagel 1986). Yet this point of view can only be attained once any privileged point of view has been transcended, whether of an animal or a mere organism. A non-sensory experience of the environment expressing that perspective consists therefore in the subject's insignificance and aesthetic aloofness. "From that perspective one experiences the world from any of an infinite number of points of view from which the viewer and, generally by parity, we do not matter at all. This gives us Nature as categorically other than us, a Nature of which we were never part" (Godlovitch 2004, 121). It is precisely through an experience free of any specific point of view that the viewer is insignificant and that nature can be seen as totally foreign and self-sufficient, and completely detached from us.

For Godlovitch, as I have said, an experience of the view from nowhere with an attitude of insignificance and aloofness is a non-sensory experience. It appears to be so because, through insignificance, the subject of perception has vanished from the experience. But it

\footnotetext{
${ }^{5}$ Godlovitch thinks that all forms of centrism fail to grasp nature as a whole. Patho-, bio- and even eco-centrism are all conceptions that perceive nature in a particular way and are only perspectives, clearly broader than anthropocentrism but nevertheless always one-sided and representing specific interests. Nature-with a capital "N" in Godlovitch's vision-has "neither parts nor tradition nor history" (Godlovitch 2004, 110). A truly acentric environmentalism thus requires in his view an acentric aesthetic that is alone capable of grasping nature as it really is.
} 
also appears that through aloofness it is the world that vanishes, through its radical externality. If this interpretation is correct, we must recognize that this conception of an acentric aesthetic is curious to say the least; it borders on an oxymoron. For it is hard to see in what way it would still constitute not only an aesthetics of nature but also an aesthetics of nature. With his understanding of the view of nowhere, Godlovitch leaves nature on one side and sensibility on the other. For Carlson, aesthetic experience is non-sensory because the viewer is a knowing subject regarding a known object-the environment. But what is left of aloofness in the sense implied by Godlovitch? Nothing at all-the radical externality of nature implies that there is no longer a correlate for aesthetic appreciation. In this conception of aloofness, Godlovitch's acentric aesthetic turns, in my view, into an aesthetics of existence for which nature no longer holds any importance. And in so doing, it is the human subject that no longer has its place in nature.

On reflection, Godlovitch's conception of the insignificance of the subject and the world's aesthetic aloofness could prove to be an inaccurate conclusion (externalized vision, radical difference from nature) inferred from true premises (the absence of a privileged point of view, insignificance and aloofness). We can try to reconstruct Godlovitch's inference in the following way: a truly acentric aesthetic requires a perspective from nowhere (or the absence of a privileged point of view); this perspective is demonstrated through insignificance and aloofness; from these two premises, a conclusion is then inferred according to which nature is radically exterior to and different from us. Consequently, depending on the sense given to the first premise (a residue of objectivism), it will influence the second premise (an attitude of aloofness and insignificance), which, together with the former, will determine the conclusion (nature as radically other).

An objectivist bias regarding acentrism would thus explain the radical sense attributed to the concept of aloofness. Nevertheless, unless one takes into consideration certain psychological pathologies, it is in fact impossible to be aesthetically detached in the sense intended by Godlovitch, in other words to feel completely external to nature. The author seems to give in to what philosopher of science Michel Bitbol calls a scientific "blind spot" (Bitbol and Eliasson 2014, 8). This expression evokes the oversight-constantly recalled by phenomenologists - that nature always exists for a consciousness, which is not necessarily a subject, an I. The philosophical tradition of phenomenology can help to correct Godlovitch's conception of acentric aesthetics on this point.

Thus, if this aesthetic aspires to be an environmental aesthetic, it must refer to a sensorial experience of nature, ${ }^{6}$ while being an experience of the view from nowhere. The latter indeed supposes the insignificance of the subject. It also presumes a form of aloofness. However, I suggest that this aloofness does not signify externality with regard to nature:

\footnotetext{
${ }^{6}$ Godlovitch feels that while science may reach beyond human sensibility, it remains subject to human frameworks in attempting to understand the world as it is (2004, 116-117). In this sense, it humanizes nature. In his view, only an aesthetic attitude of insignifiance and aloofness makes it possible to go beyond a human perspective. Yuriko Saito $(2004,144)$ perceives very well such a challenge when aesthetic experience of nature, like in acentric experience, is seen as non-sensory aesthetic experience: "our aesthetic experience, she says, begins and ends with the sensuous surface" (149). In her view, this need for sensibility in aesthetic experience does not prevent one from appreciating nature "on Its Own Terms" (as in the title of her article), whether due to scientific knowledge, myths or indigenous and folklore traditions.
} 
one can be detached from inside the world by simply giving oneself over to whatever arises. ${ }^{7}$ And the latter can be apprehended from a perceptive experience referring to a body rather than to a subject or self-awareness. All things considered, we should be thinking about a different conception of the view from nowhere. Nagel sees the view from nowhere as coming from the natural sciences. As for me, I propose seeing it as coming from pure experience (Nishida 1990, 3-4), in other words, unfiltered by any subject (knowing, psychological, social) - outside of all thought or judgment, and coextensive with the world.

\section{Acentric Aesthetic Experience from a Phenomenological Perspective}

To my knowledge, research by the French philosopher Merleau-Ponty is rarely evoked in discussions on environmental aesthetics. Mentions can be foundin Berleant's work (1992), for example, or more recently in Klaver (2014), Cooper (2016), and Jóhannesdóttir (2016). The originality in his way of thinking lies in its disclosure of a layer of lived experience of the world that involves a sensing through my own body: I sense the world, in other words I see the brightly colored oak leaves in the autumn, I hear the wind rustling through the trees in the woods, I smell the air after a storm, etc. There is a conscious life apart from one's personal life. This conscious life is that of my body-of my eyes, my hands, and my ears (Merleau-Ponty 2012). By revealing the existence of a lived body, Merleau-Ponty contributed a great deal to de-objectifying the world, which ultimately remains a world perceived through our bodies.

However, in his 1945 work The Phenomenology of Perception, the world remains "still a world as intended by a subject" (Brook 2005, 356). In particular in his posthumous work from 1964, The Visible and the Invisible, Merleau-Ponty strives to radicalize the process of de-objectifying the world by introducing the concept of flesh. The book completes the job of dissolving subjects as ontologically separate from nature by returning to the lived body.

Where are we to put the limit between the body and the world, since the world is flesh? Where in the body are we to put the seer, since evidently there is in the body only "shadows stuffed with organs," that is, more of the visible? The world seen is not "in" my body, and my body is not "in" the visible world ultimately: as flesh applied to a flesh, the world neither surrounds it nor is surrounded by it. A participation in and kinship with the visible, the vision neither envelops it nor is enveloped by it definitively. The superficial pellicle of the visible is only for my vision and for my body. But the depth beneath this surface contains my body and hence contains my vision. My body as a visible thing is contained within the full spectacle. But my seeing body subtends this visible body, and all the visibles with it. There is reciprocal insertion and intertwining of one in the other. (Merleau-Ponty 1968, 138)

\footnotetext{
${ }^{7}$ This mental state is the last phase in the phenomenological method as described in detail by Depraz, Varela, and Vermersch $(2003,37-41)$ and Bitbol $(2014,161)$ : a phase of "letting go" in which one opens up to the unheard of, to what has not yet been subjected to any categorization or conceptual objectification. Note that this phase is preceded by two others: suspending intentionality toward the world (the epoché) and shifting attention to acts of consciousness.
} 
This notion of flesh, the expression of a non-dualist ontology, has given rise to two interpretive schools of thought noted by Bryan E. Bannon (2011). The first suggests understanding flesh from perceptive experience. As flesh, the body apprehends itself as perceiving things in the world and, through that very perception, as a thing among the things in nature. In doing so, it lives as part of the world, incorporated within it; it experiences itself as part of nature. Nevertheless, while seeing, touching and smelling nature, it is nature that sees it, touches and smells it, precisely because it is part of the sensible it perceives. Sensing, the body is also sensed; and it is not only sensed by itself, but also by the whole sensible, because by feeling the sensible, starting with its own body, it belongs to that sensible and is surrounded by it. This version of the flesh is held by Abram (1996) and Toadvine (2009) in particular, despite their numerous differences. It conceives of the world not only as a sensed world, but also as a sentient world.

The second school of thought championed by Bannon interprets flesh as an element of being, or a new definition of the essence of things. This proposition consists in freeing oneself from lived experience in order to imagine the flesh in purely relational terms where "flesh is a manner in which a body relates to others through its immediate contact with them" (Bannon 2011, 344). The flesh of a thing is the core or relational field through which it is open to its environment. ${ }^{8}$ In Merleau-Ponty's terms, the flesh of the world is therefore not being in itself but rather "is of the Being-seen, i.e. is a Being that is eminently percipi, and it is by it that we can understand the percipere" (Merleau-Ponty 1968, 250). In relation to the body itself, the flesh of the world means that "this perceived that we call my body applying itself to the rest of the perceived, i.e. treating itself as a perceived by itself and hence as a perceiving, all this is finally possible and means something only because there is Being, not Being in itself...but the Being that also contains its negation, its percipi" (MerleauPonty 1968, 250-251).

These two interpretations of flesh nevertheless clearly suppose a form of reflexivity inherent in the body. That reflexivity is at work in the duplicity of sentience, evoked earlier by Merleau-Ponty, between the sentient and the sensible, between the seer and the visible. Although seeing, the body itself is a visible thing, and as a visible thing in the visible world, it nevertheless sees. And yet this reflexivity does not prevent the "strange adhesion of the seer and the visible" (Merleau-Ponty 1968, 139), which the author understands as a reversibility of sensing between the sentient body and the sensed body. ${ }^{9}$ To use MerleauPonty's paradigmatic example, between my right hand touching an object and my right hand touched by my left hand, there is reversibility, but it is "always imminent and never realized in fact" (Merleau-Ponty 1968, 147). That imminence is due to the non-simultaneity of the two experiences. Thus, reversibility does not involve a coincidence between the sentient body and the sensed body. A distancing that is both temporal and reflective, however subtle, prohibits it. ${ }^{10}$

\footnotetext{
${ }^{8}$ Note that this same idea of a relational field is also present in Naess's work (1989, 54-55).

9 Merleau-Ponty uses other words too in The Visible and the Invisible to express this idea: "intertwining" (130), "chiasm" (130, 160), "ramification" (136).

${ }^{10}$ I do want to mention in this context the original and recent attempt of Sparrow (2015) to work out a postphenomenological conception of lived body in nature which replaces Merleau-Ponty's reversibility of flesh by plasticity. Based on the non-phenomenological layer of sensation (accessible through its effects), bodies are
} 
And yet, doesn't Merleau-Ponty's reminder quoted above that "there is Being" lead us to suppose all the same a kind of coincidence at the very core of reversibility between the sentient and the sensed? This hypothesis strives in fact to combine the two schools of thought described earlier by Bannon: it sees the flesh of the world as a physical experience, but a non-reflective one, signifying being, not the perceived being yet, but being that contains its own negation, its percipi, before unfolding. Thus, it consists in bringing together the two interpretive options instead of opposing them, by trying to mitigate them through each other. This is not what Merleau-Ponty says, but rather what he might have said, after ridding himself once and for all from any references to the Cartesian cogito.

Indeed, in The Visible and the Invisible Merleau-Ponty gives up on defending the idea of a tacit cogito, an idea still present in Phenomenology of Perception (1968, 170-171). Outside the visible world, of the percipi, one finds not being in itself, but the actual, fleeting and instantaneous emergence (or arising) - here and now-of a "there is Being." Acknowledging the possibility of that simple actuality, in the present moment, of the experience of being in the moment when it occurs, prompts the thought that the reversibility of sentience indeed confirms a form of coincidence-specific to the flesh-between the sentient body and the sensed body, between the seer and the visible. This coincidence occurs outside the inevitable distance introduced by reflexivity and temporality.

It is true that Merleau-Ponty doesn't talk about a coincidence between the sentient and the sensed. However, he suggests that "nothing" separates them, "the 'Nothing,' the 'Void,' which has the capacity for receiving the plenitude of the world, or either which needs it to bear its own emptiness" $(1968,52)$. This "nothing"-which is thus not nothing-provides the justification for introducing the idea of a coincidence within the reversibility of the sentient in the context of an aesthetic of nature characterizied by the appreciation of nature "on Its Own Terms" (Saito 2004, 141) and by the insignificance of the subject and aloofness. Such an aesthetic indeed reveals the "nothing" as being the very stuff of that coincidence. If such is the case, how can it manifest on the reflective level, knowing that it characterizes the experience of being in the present moment as it arises? Two reflective modalities of sentience seem to be rooted in this experience and to preserve its flavour: the imagination and expression.

The flesh, as I said, designates the "sensed world" (through the sentient body), a world which, through my body's being part of the world is the "sentient world." The "is" translates a double dynamic: on the one hand, an imaginative coincidence between the sentient body and the sentient world through the sensible; on the other hand, an expressive coincidence between the sensed world and the sentient world through experience. With regard to imaginative coincidence, it appears to prompt two of the four modalities of imagination clearly identified by Brady (2004, 162-163): first there is the ampliative imagination that creates and invents new ways of seeing through an amplification of what is perceived by going beyond the mere projecting of images. It combines visualizing and leaps of imagination, making it possible to consider natural objects from totally new points of view.

"plastic" in so far as they are material. Such a plasticity enables therefore a new vision of the aesthetic relation between self and its environment. In contrast, my view is not post-phenomenological but hyperphenomenological in that, like Sparrow, it points at a non-reflexive level of the lived body but maintains at the same time the transcendental status of it. 
Revelatory imagination is then the inventive power of the imagination taken to its limit and, for Brady, "this often gives way to new ideas and meanings; revelation in the non-religious sense" $(2003,157)$. This kind of imagination is very close to what Ronald Hepburn calls the "metaphysical imagination" which allows us, for instance, to see landscape as "cosmically ominus" $(2004,127)$ and to experience aesthetically stones, leaves, and clouds, as well as nature as a whole.

As for expressive coincidence, it designates here, according to Merleau-Ponty's definition of the expression, "the property of a phenomenon, through its internal organization, to make known another [phenomenon] that is not or never has been known" (Merleau-Ponty 2011, 48). ${ }^{11}$ In this sense, the sensed or perceived world is an expression of the sentient world; it "contains that emerging truth about the world" generated by the ampliative and revelatory modes of the imagination (Merleau-Ponty 2011, 48). Thus, expression is not the result of a projection through which one sees the sensed world like the sentient world. It is not an interpretation of the sensed world, but an immediate perception of the sentient world in the sensed or perceived world. That said, there is nothing to prevent an interpretation of this immediate perception at a later date. The view from nowhere, which is to say the absence of any particular perspective or the world as a whole, can therefore be expressed in my physical, sensory experience. It is so because my body is part of the sensible world, which is the stuff that feeds my imagination.

The double-imaginative and expressive-coincidence described above is fostered in certain situations, or in the case of certain natural events: I can see the origin of life in the color or shape of a sunrise or the immensity and infinity of space in the deep and clear view from the top of a mountain; I can feel the seasonal atmosphere in the rain on my face during a summer storm or in the smell of lilacs when walking in the spring; I can touch the matter of the universe itself in the texture of the granite when I am rock climbing; I can hear Earth's elemental forces in the wind howling past two cliffs in the mountains or in the silence of the desert; and so on. But, in principle, perception of all natural phenomena can become an expression of the view from nowhere, as evidenced by Whitman's verse quoted at the beginning of this essay: gneiss, fruits, coal, long-threaded moss, the esculent roots.... ${ }^{12}$

To conclude, the flesh of the world-beneath the illusory duplicity between the sentient body and the sensed body-constitutes a pure experience. On an imaginative and expressive level, the latter is immediate and without thought (reflexion) or judgment, ${ }^{13}$ where the difference between the subject and object has not yet occurred (Nishida 1990, 3-4; Bitbol 2014, 55-56). ${ }^{14}$ I do not perceive the colour and form of a sunrise first in order to then

\footnotetext{
${ }^{11}$ See also Cassirer's (1965) notion of the function of expression.

${ }^{12}$ The famous passage from A Sand County Almanac titled "Thinking Like a Mountain" where Leopold tells his experience of a she-wolf's death can be interpreted as a prelude of such a coincidence. In watching the fierce green fire in the eyes of the wolf, Leopold perceives "something new" $(1949,130)$, something which he will understand few decades later: the ecological point of view of the mountain itself.

${ }^{13}$ For Godlovitch (1998) aesthetic appreciation does not necessarily involve an evaluation or an aesthetic judgment.

${ }^{14}$ In supporting the idea that acentric aesthetic experience is a pure experience, my aim is to underline the particularity of the perception of the mystery of nature. Such an experience radicalizes the process of de-
} 
interpret it as the origin of life. The colour or form of the sunrise expresses the origin of life in the very present moment of the act of seeing. In the aesthetic attitudes of aloofness and the insignificance of the subject, the actual sightof the color or form of a sunrise is both the point of departure for imaginative activity and the point of arrival of the expressive activity. These two activities are indissociably condensed in the present moment of perceptive consciousness. In an acentric aesthetic experience of nature, marked by the subject's insignificance and aloofness, nature also becomes the flesh of the world, but a flesh that is a pure experience; in other words the very actuality of a perceptive act that joins (ampliative, revealing) imagination and expression without distinguishing them.

Furthermore, an acentric aesthetic experience is ineffable not in the sense in which the sensed world would be (the colour of a sunrise, the clear view from the top of a mountain, the texture of granite, etc.), but in the sense where the sensed world is the expression of the sentient world (the origin of life, the immensity and infinity of space, the matter of the universe, etc.), i.e. the view from nowhere that is also the view from an infinity of points of view. ${ }^{15}$

Reconsidered through the prism of this interpretation of the flesh of the world, acentric environmental aesthetics shows what I propose to call the "invisible" aspect of flesh, in other words the mystery of nature. Through the viewer's insignificance and aesthetic aloofness, due to the physical sensations produced by the sensible world, it is the world itself as a whole that is expressed in those sensations. It does so according to its own point of view-the view from nowhere-but always and only through the imagination. By becoming insignificant to myself, I return to that physical state of sensations apart from my personal life and social identity. By becoming aesthetically aloof from the world, I adopt the mind's point of view, but from inside the world, through my body. That aloofness is ultimately analogous to what the stoic sages advocated. An acentric aesthetics of nature, as proposed through phenomenological exploration, as such resolves in its way-via the imagination - the issue of the relationship between mind and matter. Insignificance and aesthetic aloofness dispel the very issue at hand.

\section{Death and the Mystical}

Godlovitch advocates the idea that an acentric aesthetics of nature striving to transcend the observer's point of view is similar to a truly mystical attitude, and even to death. Unfortunately, he doesn't delve any deeper into these two themes. To distinguish his

objectifying nature. It contrasts with other aesthetic experiences, such as of the picturesque or the beautiful, which are always experiences of natural objects.

${ }^{15}$ The flesh of the world as a pure experience is inexpressible in the sense that the sensed world-through physical sensations-is the expression of the sentient world; in other words, from the point of view of the world itself, which, in Nagel's terms evoked at the beginning of this essay, is translated by the "what it is like to be neither this nor that." This is not a matter of semantic or incommunicable ineffability, to adopt Spackman's enlightening distinction (2012), since both expressive qualities (this sunrise here, that howling wind there, etc.) and the point of view from nowhere (what it is like to be neither this nor that) are demonstrative concepts. On the other hand, pure experience is descriptively ineffable in the sense that no description (the origin of life, the immensity of space, seasonal atmosphere, etc.), however exhaustive, and whether literal or metaphorical, can capture that experience. About the link between ineffability and mystery, see Cooper (2007, 286-295). 
approach from other versions of acentric aesthetics, Godlovitch qualifies it as "objectivemystical" $(2004,112)$. In using the word "mystical," he seems less to be suggesting a feeling of union than a practical attitude, specifically of insignificance and aloofness. ${ }^{16}$ The observer's insignificance alludes to the idea of a radical decentering of the self, a selfrenunciation so great that it exhausts any subjective perspective. In its place, there remains only a simple experience of the world, from which any particular point of view has disappeared. In this, it is similar to numerous accounts relating to mystical experiences of nature, which I will re-examine later. For the moment let us bear in mind, as Godlovitch points out, that this is not about "taking a God's-eye view" $(2004,123)$.

Aesthetic aloofness, for its part, is meant to help us see the world as indifferent to our own interests and preoccupations. In regarding the world from a beetle's view, we shall have done the most important thing, Godlovitch suggests. Finally, the author thinks that through death we come closest to the mystery of nature. But then, he adds, "that robs the actor of the play, the audience of the actor" $(2004,122)$. The reader will learn nothing more.

Can the phenomenological approach adopted earlier teach us anything more about death and mystical attitudes? What parallels does it allow us to make between such subjects and an acentric aesthetic experience of nature? In the final part of this essay, I would like to outline some answers to these questions.

\subsection{Death}

Death has been one of the main preoccupations of human existence since the appearance of Homo sapiens, in evidence in all cultures and during all eras of humanity. There are at least two aspects of a phenomenology of one's own death: one aspect is temporality and the second is so-called "near-death experience." ${ }^{17}$ Let us first consider temporality. In his one-of-a-kind book, La face cachée du temps ("The Hidden Face of Time"), the philosopher and Indianist Michel Hulin (1985) begins by emphasizing that death is not only an empirical phenomenon; it is above all something necessary to our being, and prolonging life, even for several centuries, would not change anything. But Hulin notes that the contrary-"nondeath" - is equally necessary: I cannot die in that I am not the subject of the action of dying. To lose your life, you have to be there to lose it. But if there is no loser, there is nothing to lose.

According to Hulin, this non-death is closely linked to the structure of temporality. The present moment is only real with regard to a future that is getting closer to the present and to a past toward which the future is aiming. That flow of time makes the very idea of a "last moment" inconceivable. "Going beyond time...cannot be accomplished from within time itself, by its being interrupted or stopped. Time can only be considered eliminated to the extent that an individual consciousness would also be absent which, from its dwelling place in the present moment, infinitely unfolds past and future dimensions. But in no way can

\footnotetext{
${ }^{16}$ However, as we will see later on, insignificance and aloofness presuppose such a union.

${ }^{17}$ This last expression was introduced by the philosopher and psychiatrist Raymond Moody with the publication of his book Life after Life in 1975. The author developed the first model of such an experience which, incidentally, did not contain any speculation yet about the existence of a possible hereafter. The book has since prompted a great deal of hotly debated research and publications.
} 
that absence take the form of dying understood in an absurd manner as the process through which consciousness leaves time" (Hulin 1985, 28-29).

How then to resolve the apparent contradiction between the necessity of death and the necessity of non-death? Through the presence of the "infinite in the finite," answers Hulin $(1985,29)$. I can certainly imagine my future death, but I cannot visualize my own death in real time. This inaptitude is a symptom, in the present, of a "consciousness of another order," of a "universal Witness" for whom every moment in time is "now" and every part of space "here" $(1985,32)$. This Witness is not outside time and space, but that from which time and space unfold. It is the condition that makes possible a shared world and intersubjectivity, and constitutes in that sense the "impersonal part of my being" $(1985,33)$ which I share with all other finite consciousness. However, at the same time, it is what is most specific to me, as if my individual existence in space and time were only a pale physical, psychic and social reflection of it. The other necessity, which makes me a "Beingtoward-death," as Martin Heidegger said, recalls that I do not coincide with the Witness; through my individual existence in time there is a gap with the Witness that it is death's role to fill in.

The double impossibility with respect to death, observed by Hulin, can be confirmed by numerous accounts, in particular by those who have undergone what is now called a "neardeath experience." Such an experience is the second aspect of a phenomenology of own death. ${ }^{18}$ However, for my purposes it seems one just has to examine the analogy between the structure of a (near-)death (or non-death) experience and that relating to an acentric aesthetic of nature in the phenomenological sense. As I wrote earlier, an experience of the flesh of the world translates a double coincidence-an expressive coincidence between the sensed (or perceived) world and the sentient world (the view from nowhere), and an imaginative coincidence between the sentient body and the sentient world. Indeed, in a death (or non-death) experience, the Witness is expressed in the sensed world through lived experience, being merely the impersonal layer of my subjective awareness and that of others.

However, at the same time there is another type of coincidence in this experience, between the sentient body (or physical awareness) and the sentient world. It no longer pertains to the imagination, but to life: it is the moment when I reach the point of coinciding with the Witness, in other words the moment of my death itself, when my body becomes a simple worldly object. At that point, there is no lack of any point of view; the sensible-and especially my body-is perceived through a perspective with no particular point of view. Such a perspective is expressed in well-attested features of near-death experience. ${ }^{19}$ What

\footnotetext{
${ }^{18}$ Relatively recent and well-regarded books on the subject include: Braude (2003), Williams Kelly, Greyson, and Kelly (2007), Corazza (2008), Sartori (2008), van Lommel (2010), Parnia (2013), and Woollacott (2015). For recent critical studies, see Engmann (2014) and Fischer and Mitchell-Yellin (2016).

${ }^{19}$ As showed by Bitbol $(2014,673)$ two interpretations of near-death experience are possible. They are understood either as false narratives of an experience whose illusory reality is due to physiological or psychological dysfunction or as true narratives of an experience whose reality is then supranatural. Yet, Bitbol notes, "both interpretations present a common feature of great importance. They attribute an objective ground to narratives, a material one or a transcendental one" (674). A strictly phenomenological perspective, on the contrary, strives to consider them for what they are: narratives of an experience from a "first-person" perspective whose characteristics are on one hand exclusivity (the dying situation) and on the other hand self-
} 
an aesthetic experience of the flesh of the world realizes about the world through imagination, the experience of death (or non-death) ultimately realizes through existence. Through different modalities, they are both experiences of the mystery of nature.

\subsection{The Mystical}

Is there an analogy for the mystical like the one described above? We can start by noting that mystical phenomena are very hard to define the scope of or to characterize on a phenomenological level, given their protean manifestations and the religious interpretation often attributed to mystical experiences by those who have them. Nevertheless, for more than a century several philosophers and historians of religion, including Rudolf Otto, Robert C. Zaehner, Walter T. Stace and, more recently, Paul Marshall, have taken on the complex task of describing these phenomena, highlighting significant features despite numerous cultural, religious, and idiosyncratic differences.

An initial, well-established distinction can be made between introverted mystical experiences, often acquired through particular techniques and dealing with the mind, and extraverted mystical experiences, often spontaneous and aimed at the outside world (Stace 1961, 60-61). Only the latter have been taken into consideration here, since extraverted mystical experiences are none other than mystical experiences of nature. The essential feature of such experiences is a perception of the sensible world in its multiplicity, with an intuition of its unity. This unity is experienced in different forms: as a whole, as a paradoxical identity of things or as an identity between the subject and object/the world (a union), as an eternal present, or an expansion of the field of consciousness, or even a kind of transcendence of time and space (Marshall 2005, 50-59).

Here again, the parallel linking a mystical perception of the world-of its unity in multiplicity-and an expressive coincidence between the sensed world and the sentient world within an acentric aesthetic experience is striking. What nature shows are things themselves, not from the observer's point of view in their sole diversity. They are perceived in their unity, in other words from a perspective that is not specific, one that transcends the subjective, fragmented vision we usually have. But how does one reach that point of view from nowhere in a mystical experience?

In an acentric aesthetic experience of the flesh of the world, there is another type of coincidence between the sentient body (or physical awareness) and the sentient world. This type of coincidence is imaginative because it involves an experience of the flesh of the world. ${ }^{20}$ Another coincidence occurs in extraverted mystical experiences, but without using the imagination. It is often based on the sensed world or the sensible, or more directly on

transformation (long-time effects on the perception of sense of life, choices, and so on). Therefore, if one is sensitive in appearing of such experiences (and not in what appears) it can be taken in account of what an eminent researcher says about near-death experiences. Van Lommel (2010, 224-225) indeed describes some lines of a near-death experience-out-of-body perception, life review, preview and transition from darkness to light-as non-local phenomena, that is interconnected out of time and space.

${ }^{20}$ In an acentric aesthetic experience of nature, the imagination is awakened by the flesh, which, through a form of envelopment, is both my flesh and the flesh of the world. Nothing equivalent occurs in an extraverted mystical experience where expressive coincidence seems to pertain to an intuition from the subject rather than from the sensible itself. 
the sentient body through spiritual practices and other psychological and physiological states (Marshall 2005, 82-107). Nevertheless, contrary to introverted mystical experiences, extraverted mystical experiences are fortuitous, generally occurring in a spontaneous manner with no particular preparation. Thus, there is nothing here that could contribute to the coincidence between the sentient body and the sentient world, except for consciousness at its most basic, namely "phenomenal" consciousness or, in Nagel's terms, "There is something it is like to be...."

In that respect, the structure of extraverted mystical experience is similar to the experience of death (or non-death). In both cases, the coincidental event occurs without any mediation. In an experience of death (or non-death), it is the occurrence of one's own death that creates the (existential) coincidence. In extraverted mystical experience it occurs in the present moment of bodily awareness. I describe that coincidence as "spiritual" because it highlights the psychic aspect of the sensible world; it then implies the idea that this modality of coincidence between the sentient body and the sentient world, between phenomenal consciousness and the point of view from nowhere, involves renunciation, letting go and decentering. The essence here does not reside in personal identity or self. This seems to be a constant in all forms of mystical experience. Some, such as the contemporary mystic Bernadette Roberts (1993), have for this reason called it an "experience of no-self." To conclude on this point, through an extraverted mystical experience we encounter the mystery of nature in a different way than through the experience of death (or non-death) or an acentric aesthetic experience. ${ }^{21}$

Consequently, to my mind Godlovitch is absolutely right in evoking death and the mystical with regard to an acentric aesthetic experience of nature. That proximity can be confirmed through a phenomenological approach. Acentric aesthetic experience, the experience of death (or non-death) and extraverted mystical experience constitute three modalities of a pure experience of nature during which the point of view from nowhere is expressed in the sensible: as three forms of experiencing the mystery of nature. Moreover, all three are marked by the insignificance of the subject and aloofness.

And yet they are not identical. Acentric aesthetic experience differs from the other two in that the point of view from nowhere as expressed in the perceived world is mediated through the imagination. This form of mediation is not present in an experience of death (or non-death) or in extraverted mystical experience; the former is of an existential nature, and the latter of a spiritual nature. These two experiences are in fact pure experiences par excellence, since both bypass the mental and affective activity of the imaginationin their perception of the world's expressivity: the point of view from nowhere is expressed in nature either existentially through my own dying, in other words my death experienced as that of the physical body of another, due to the coincidence with the Witness; nor it is expressed spiritually through a decentering of the self, in other words an "experience of no-

\footnotetext{
${ }^{21}$ Described in this way, mystical experiences of nature echo the "hard problem" evoked by David Chalmers with regard to consciousness, namely why cognitive and behavioral functions come with phenomenal experience (whether subjective or not). Colin McGinn (1991, 2004) and Mark Rowlands (2001) deem it scientifically insoluble.
} 
self." ${ }^{22}$ In addition, contrary to acentric aesthetic experience, experience of death (or nondeath) or extraverted mystical experience are almost always the object of an interpretation of that mystery, whether in religious, scientific (psychological, biological, anthropological, etc.) or philosophical terms. ${ }^{23}$ The aesthetic specificity of acentric aesthetic experience consists precisely in aesthetically experiencing that mystery-with no finality other than the experience itself-by deliberately abstaining from interpreting it.

\section{Conclusion}

In this essay, I have proposed an alternative interpretation to the mystery of nature model developed by Godlovith. To that effect I have drawn inspiration from Merleau-Ponty's notion of flesh. The key issue in this development has consisted in providing aesthetic meaning to the concept of the ecological self advanced by Naess and thus helping to establish its legitimacy. In so doing, I feel ultimately that the alternative suggested for Godlovitch's model has a relationship analogous to that of Naess' conception toward Reed's. If attitudes of insignificance and aloofness are indeed characteristics of acentric aesthetic experience, I do not believe they lead to seeing nature as an externality categorically different from us. Godlovitch describes his understanding of acentric experience as "mystical." Yet, as we have seen, the idea of unity, in whatever form, is a key feature of mystical phenomena. It is hardly compatible with an external point of view of the world; nor is an experience of death (or non-death). Furthermore, as we know from the theory of evolution and scientific ecology, we are an integral part of nature. A satisfactory aesthetic theory of the environment must be in line with this holistic vision of things.

It thus appears that the debate between Reed and Naess on an adequate concept of the human relationship to nature leads us to opt for Naess's vision. Humans are not apart from nature, as Reed asserts; on the contrary, humans are part of it. A phenomenological version of acentric aesthetic experience thus supports the idea according to which deep ecological self-realization is a fertile vision of what it means to belong to nature. And this realization implies a process of identification in which the well-being of others is tied to one's own wellbeing (Naess 1989, 175; 1999, 200).

Through phenomenology I have tried to show that it is possible to imagine an acentric aesthetic experience without necessarily placing oneself outside nature. A point of view

\footnotetext{
${ }^{22}$ Expressive content of death (or non-death) experience and extraverted mystical experience are no more mediated by imagination-a subject who imagines. While apparently presenting a mental and affective dimension, it becomes the content of an experience without subject (death, no-self).

${ }^{23}$ On a philosophical level, my intention in this essay is limited to a so-called "narrow" or "strict" phenomenology because the descriptions are those of a lived body in nature and of what appears to it. However, such a phenomenology could be extended with metaphysics of nature by Robert S. Corrington $(2016,2017)$, who calls it "ordinal phenomenology" (2017, xii). Relative to an ecstatic naturalism (Corrington 1994) ordinal phenomenology describes nature in its twofold aspect: as naturanaturans, which means the creative and hidden dimension of nature, and as naturanaturata, which are uncountable orders and components of the world (material, biological, economical, artistic, pragmatic, spiritual, and so on). Yet naturanaturans and naturanaturata are encompassed by nothingness. In this context, ecological self and my aesthetic interpretation of it is close to the process described by Corrington in his ordinal phenomenology as "Selving process" (2016, xxiii-xxiv). In ecological self-realization humans are also in tension between their place in naturanaturata (a body in nature) and the potentialities of naturanaturans (the view from nowhere).
} 
from nowhere that goes beyond any privileged perspective can be adopted from inside the world, as close as possible to it. Yet, it still requires the subject's insignificance and aloofness. Have we returned, then, to the very anthropocentrism that Godlovitch wished to transcendand that Naess rejects categorically? Clearly the posture has nothing to do with moral anthropocentrism. And yet, doesn't a phenomenological interpretation of acentric aesthetic experience entail a form of anthropocentrism that could be described as "epistemic"? I do not think so. The anthropocentrist bias arises more in creations of the human psyche, societies, or culture than through the lived body; whereas a practical stance in an acentric aesthetic of nature-insignificance and aesthetic aloofness -involves ridding oneself of the cultural, social and psychological frameworks through which nature is apprehended. ${ }^{24}$

Moreover, the phenomenological approach has shown that an acentric aesthetic experience of nature is a pure experience. The mystery of nature comes to light not through categories of the mind, but in an experience that is both de-objectified and de-subjectified. This is clearly confirmed in the close kinship between an extraverted mystical experience and acentric aesthetic experience.

This developmentas a whole suggests that an acentric experience of nature as we have explored it is in a sense an aesthetic equivalent of the ecological self. And, just as identification underlies the ecological self, the double-imaginative and expressivecoincidence underlies acentric aesthetic experience. To employ Naess's terms, "deep, comprehensive ecological" self-realization consists in going beyond the subjective human point of view in order to see human and non-human interests as one's own. However, a phenomenological model of acentric aesthetic experience allows us to go further: as I see it, self-realization aims in fine to achieve the view from nowhere as I have attempted to define it. This point of view now appears to be an indispensable condition in bringing together various interests, or certain of them: I can only envision legitimately bringing together human and non-human interests such as those of the ecological self by situating myself-for a moment at least-beyond the human and non-human point of view. In so doing, this aesthetic approach also shows the proximity that the ecological self has, on the one hand, to the fundamental biological life cycle of birth and death, and on the other hand, to mystical experience, without being identical to it.

In conclusion, as a phenomenological version of the aesthetics of the mystery of nature prompts us to think, the ethical ramifications of the ecological self extend beyond the question of otherness and identity, contrary to what has been maintained (Plumwood 1993, 173-182; 1999). I do not believe the mystery of nature lies in its otherness, as Godlovitch or Reed maintain. Nature's otherness is not mysterious: it is, and it is simply a matter of recognizing that when such a relationship occurs. The true mystery is elsewhere. It is experienced through the fact that nature surrounds us, that it contains us and that, despite everything, we can have that holistic experience. The mystery of nature is the fact that

\footnotetext{
${ }^{24}$ This debate is accurate in some interpretations of the last work of Merleau-Ponty, The Visible and the Invisible (James 2016). I think this work goes beyond epistemic anthropocentrism. As Simon J. James writes: "the guiding question is no longer 'What is perceived?' but 'Who (or what) is perceiving?.' ... What we misleadingly call our experience is the manifestation of some wider and deeper upsurge of being" (James 2016, 50).
} 
there is experience in nature and that nature is experience (Mathews 2003). ${ }^{25}$ Rather than an experience of the world's otherness, it is more fundamentally the condition that makes it possible. An acentric aesthetic experience of nature is the living experience of that mystery. $^{26}$

\footnotetext{
${ }^{25}$ Such an experience obviously is not necessarily a human one. Moreover, note that the formulation condenses the two approaches described by Reed (1989): humans as part of nature and nature as part of humans. Also see footnote 1 above.

${ }^{26}$ I thank warmly Emily Brady for helpful comments on a previous draft of this paper and William Snow for his support in translating it into English.
} 


\section{Works Cited}

Abram, David. 1996. The Spell of the Sensuous: Perception and Language in a More-ThanHuman World. New York: Pantheon.

Bannon, Bryan E. 2011. "Flesh and Nature: Understanding Merleau-Ponty's Relational Ontology." Research in Phenomenology 41: 327-357.

---, ed. 2016. Nature and Experience: Phenomenology and the Environment. London/New York: Rowman \& Littlefield.

Berleant, Arnold. 2004. "The Aesthetics of Art and Nature." In The Aesthetics of Natural Environments, edited by Allen Carlson and Arnold Berleant, 76-88. Peterborough: Broadview.

Bitbol, Michel. 2014. La conscience a-t-elle une origine? Des neurosciences à la pleine conscience: une nouvelle approche de l'esprit. Paris: Flammarion.

Bitbol, Michel and Olafur Eliasson. 2014. Never Known but Is the Knower. Berlin: Institut für Raumexperimente.

Brady, Emily. 2003. Aesthetics of the Natural Environment. Edinburgh: Edinburgh University Press.

- - . 2004. "Imagination and the Aesthetic Appreciation of Nature." In The Aesthetics of Natural Environments, edited by Allen Carlson and Arnold Berleant, 156-169. Peterborough: Broadview.

Braude, Stephen E. 2003. Immortal Remains: The Evidence for Life after Death. Lanham: Rowmann \& Littlefield.

Brook, Isis. 2005. "Can Merleau-Ponty's Notion of 'Flesh' Inform or even Transform Environmental Thinking?" Environmental Values 14: 353-362.

Brown, Charles S. and Ted Toadvine, eds. 2003. Eco-Phenomenology: Back to the Earth Itself. Albany: State University of New York Press.

Carlson, Allen. 1977. "On the Possibility of Quantifying Scenic Beauty." Landscape Planning 4: $131-172$.

- - . 1979. "Formal Qualities in the Natural Environment." Journal of Aesthetic Education 13: 99-114.

- - . 2004. "Appreciation and the Natural Environment." In The Aesthetics of Natural Environments, edited by Allen Carlson and Arnold Berleant, 63-75. Peterborough: Broadview. 
-- - 2008. "Aesthetic Appreciation of the Natural Environment." In Nature, Aesthetics, and Environmentalism: From Beauty to Duty, edited by Allen Carlson and Shiela Lintott, 119-132. New York: Columbia University Press.

- - . 2010. "Contemporary Environmental Aesthetics and the Requirements of Environmentalism." Environmental Values 19: 289-314.

- - . 2014. "Ten Steps in the Development of Western Environmental Aesthetics." In Environmental Aesthetics: Crossing Divides and Breaking Ground, edited by Martin Drenthen and Jozef Keulartz, 13-24. New York: Fordham University Press.

Cassirer, Ernst. 1965. The Philosophy of Symbolic Forms Vol. 3: The Phenomenology of Knowledge. Translated by Ralph Manheim. New Haven: Yale University Press.

Cooper, David E. 2007. The Measure of Things: Humanism, Humility, and Mystery. Oxford/New York: Oxford University Press.

- - . 2016. "Music and the Presence of Nature." In Nature and Experience: Phenomenology and the Environment, edited by Bryan G. Bannon, 175-186. London/New York: Rowman \& Littlefield.

Corazza, Ornella. 2008. Near-Death Experiences: Exploring the Mind-Body Connection. London/New York: Routledge.

Corrington, Robert S. 1994. Ecstatic Naturalism: Signs of the World. Bloomington: Indiana University Press.

- - . 2016. Deep Pantheism: Toward a New Transcendantalism. Lanham: Lexington.

---. 2017. Nature and Nothingness: An Essay in Ordinal Phenomenology. Lanham: Lexington.

Depraz, Natalie, Francisco J. Varela, and Pierre Vermersch. 2003. On Becoming Aware: A Pragmatics of Experiencing. Amsterdam/Philadelphia: John Benjamins.

Engmann, Birk. 2014. Near-Death Experiences: Heavenly Insight or Human Illusion? Heidleberg/New York: Springer.

Fischer, John M. and Benjamin Mitchell-Yellin. 2016. Near-Death Experiences: Understanding Visions of the Afterlife. Oxford/New York: Oxford University Press.

Gallagher, Shaun. 2002. "Complexities in the First-Person Perspective." Research in Phenomenology 32: 238-248. 
Godlovitch, Stan. 1998. "Evaluating Nature Aesthetically." The Journal of Aesthetics and Art Criticism 56: 113-125.

- - . 2004. "Icebreakers: Environmentalism and Natural Aesthetics." In The Aesthetics of Natural Environments, edited by Allen Carlson and Arnold Berleant, 108-126. Peterborough: Broadview.

Hadot, Pierre. 2006. The Veil of Isis: An Essay on the History of the Idea of Nature. Translated by Michael Chase. Cambridge/London: Belknap.

Hepburn, Ronald W. 2004. "Landscape and the Metaphysical Imagination." In The Aesthetics of Natural Environments, edited by Allen Carlson and Arnold Berleant, 127-140. Peterborough: Broadview.

Hulin, Michel. 1985. La face chachée du temps. L'imaginaire de l'au-delà. Paris: Fayard.

James, Simon J. 2016. "Phenomenology and the Charge of Anthropocentrism." In Nature and Experience: Phenomenology and the Environment, edited by Bryan E. Bannon, 43-51. London/New York: Rowman \& Littlefield.

Jóhannesdóttir, Gudbjörg R. 2016. "Phenomenological Aesthetics of Landscape and Beauty." In Nature and Experience: Phenomenology and the Environment, edited by Bryan E. Bannon, 187-199. London/New York: Rowman \& Littlefield.

Klaver, Irene J. 2014. "Landscapes of the Environmental Imagination: Ranging from NASA and Cuyhoga Images to Kiefer and O'Keeffe Paintings." In Environmental Aesthetics: Crossing Divides and Breaking Ground, edited by Martin Drenthen and Jozef Keulartz, 135-153. New York: Fordham University Press.

Leopold, Aldo. 1949. A Sand County Almanac. New York: Oxford University Press.

Marshall, Paul. 2005. Mystical Encounters with the Natural World: Experiences and Explanations. New York: Oxford University Press.

Mathews, Freya. 1991. The Ecological Self. London: Routledge.

- - . 2003. For Love of Matter: A Contemporary Panpsychism. Albany: State University of New York Press.

McGinn, Colin. 1991. The Problem of Consciousness. New York: Oxford University Press.

- - . 2004. Consciousness and Its Objects. New York: Oxford University Press.

Merleau-Ponty, Maurice. 2012. Phenomenology of Perception. Translated by Donald A. Landes. New York: Routledge. 
- - . 1968. The Visible and the Invisible: Followed by Working Notes. Translated by Alphonso Lingis. Evanston: Northwestern University Press.

- - . 2011. Le monde sensible et le monde de l'expression. Cours au Collège de France. Notes 1953. Genève: MetisPresses.

Naess, Arne. 1989. Ecology, Community and Lifestyle: Outline of an Ecosophy. Translated and edited by David Rothenberg. Cambridge/New York: Cambridge University Press.

- - . 1999. "'Man Apart' and Deep Ecology: A Reply to Reed." In Philosophical Dialogues: Arne Naess and the Progress of Ecophilosophy, edited by Nina Witoszek and Andrew Brennan, 198-205. Lanham: Rowman \& Littlefield.

Nagel, Thomas. 1974. "What Is It Like to Be a Bat?" Philosophical Review 83: 435-450.

- - . 1986. The View from Nowhere. Oxford/New York: Oxford University Press.

Nishida, Kitarō. 1990. An Inquiry into the Good. Translated by Masao Abe and Christopher Ives. New Haven: Yale University Press.

Parnia, Sam and Josh Young. 2013. Erasing Death: The Science That Is Rewriting the Boundaries Between Life and Death. New York: HarperOne.

Plumwood, Val. 1993. Feminism and the Mastery of Nature. London/New York: Routledge.

---. 1999. "Comment: Self-Realization or Man Apart? The Reed-Naess Debate." In Philosophical Dialogues: Arne Naess and the Progress of Ecophilosophy, edited by Nina Witoszek and Andrew Brennan, 206-210. Lanham: Rowman \& Littlefield.

Reed, Peter. 1999. "Man Apart: An Alternative to the Self-Realization Approach." In Philosophical Dialogues: Arne Naess and the Progress of Ecophilosophy, edited by Nina Witoszek and Andrew Brennan, 181-197. Lanham: Rowman \& Littlefield.

Roberts, Bernadette. 1993. The Experience of No-Self: A Contemplative Journey. Albany: State University of New York Press.

Rowlands, Mark. 2001. The Nature of Consciousness. Cambridge/New York: Cambridge University Press.

Roszak, Theodore, Mary E. Gomes, and Allen D. Kanner, eds. 1995. Ecopsychology: Restoring the Earth, Healing the Mind. San Fransisco: Sierra Club.

Rust, Mary-Jane and Nick Totton, eds. 2012. Vital Signs: Psychological Responses to Ecological Crisis. London: Karnac. 
Saito, Yuriko. 2004. "Appreciating Nature on Its Own Terms." In The Aesthetics of Natural Environments, edited by Allen Carlson and Arnold Berleant, 141-155. Peterborough: Broadview.

Sartori, Penny. 2008. The Near-Death Experiences of Hospitalized Intensive Care Patients: A Five-Year Clinical Study. Lewiston: Edwin Mellen.

Spackman, John. 2012. "Expressiveness, Ineffability, and Nonconceptuality." The Journal of Aesthetics and Art Criticism 70: 303-314.

Sparrow, Tom. 2015. Plastic Bodies: Rebuilding Sensation After Phenomenology. London: Open Humanities.

Stace, Walter T. 1961. Mysticism and Philosophy. London: Macmillan.

Toadvine, Ted. 2009. Merleau-Ponty's Philosophy of Nature. Evanston: Northwestern University Press.

Vakoch, Douglas A. and Fernando Castrillón, eds. 2014. Ecopsychology, Phenomenology, and the Environment: The Experience of Nature. New York: Springer.

Van Lommel, Pim. 2010. Consciousness Beyond Life: The Science of Near-Death Experience. New York: HarperOne.

Whitman, Walt. 1965. Leaves of Grass, edited by H. W. Blodgett and S. Bradley. New York: W. W. Norton.

Williams Kelly, Emily, Bruce Greyson, and Edward F. Kelly. 2007. "Unusual Experiences Near Death and Related Phenomena." In Irreducible Mind: Toward a Psychology for the 21st Century, edited by Edward Kelly and Emily Williams Kelly, 367-421. Lanham: Rowman \& Littlefield.

Woollacott, Marjorie H. 2015. Infinite Awareness: The Awakening of a Scientific Mind. Lanham: Rowman \& Littlefield. 